\title{
Challenges in managing the risks of chronic wasting disease
}

\section{William Leiss*, Margit Westphal, Michael G. Tyshenko and Maxine C. Croteau}

McLaughlin Centre for Population Health Risk Assessment, University of Ottawa, 600 Peter Morand, Ottawa, ON, K1G 3Z7, Canada Email: wleiss@uottawa.ca Email: Margit.Geisterfer@gmail.ca Email: mtyshenk@uottawa.ca Email: maxinecroteau@hotmail.com *Corresponding author

\section{Tamer Oraby}

Department of Mathematics, University of Texas - Pan American, 1201 W University Dr., Edinburg, TX 78539, USA

Email: tamer.oraby@utrgv.edu

\section{Wiktor Adamowicz and Ellen Goddard}

Department of Resource Economics and Environmental Sociology, University of Alberta,

Canada

Email: vic.adamowicz@ualberta.ca

Email: ellen.goddard@ualberta.ca

\section{Neil R. Cashman}

Department of Neurology, Faculty of Medicine,

Vancouver Coastal Health,

University of British Columbia, Canada

Email: Neil.Cashman@vch.ca 


\title{
Shalu Darshan
}

McLaughlin Centre for Population Health Risk Assessment, University of Ottawa, 600 Peter Morand, Ottawa, ON, K1G 3Z7, Canada

Email: sdarshan@uottawa.ca

\section{Daniel Krewski}

McLaughlin Centre for Population Health Risk Assessment, Faculty of Medicine, University of Ottawa, 600 Peter Morand, Ottawa, Ontario, K1G 3Z7, Canada and School of Epidemiology and Public Health, Faculty of Medicine, University of Ottawa, 600 Peter Morand, Ottawa, Ontario, K1G 3Z7, Canada and

Risk Sciences International, 55 Metcalfe Street, Suite 700, Ottawa, ON K1P 6L5, Canada Email: dkrewski@uottawa.ca

\begin{abstract}
This article summarises efforts at disease surveillance and risk management of chronic wasting disease (CWD). CWD is a fatal neurodegenerative disease of cervids and is considered to be one of the most contagious of the transmissible spongiform encephalopathies (TSEs). Evidence has demonstrated a strong species barrier to CWD for both human and farm animals other than cervids. CWD is now endemic in many US states and two Canadian provinces. Past management strategies of selective culling, herd reduction, and hunter surveillance have shown limited effectiveness. The initial strategy of disease eradication has been abandoned in favour of disease control. CWD continues to spread geographically in North American and risk management is complicated by the presence of the disease in both wild (free-ranging) and captive (farmed) cervid populations. The article concludes that further evaluation by risk managers is required for optimal, cost-effective strategies for aggressive disease control.
\end{abstract}

Keywords: chronic wasting disease; CWD; surveillance; cervids; transmissible spongiform encephalopathy; TSE; risk management strategies; culling; free ranging; captive.

Reference to this paper should be made as follows: Leiss, W., Westphal, M., Tyshenko, M.G., Croteau, M.C., Oraby, T., Adamowicz, W., Goddard, E., Cashman, N.R., Darshan, S. and Krewski, D. (2017) 'Challenges in managing the risks of chronic wasting disease', Int. J. Global Environmental Issues, Vol. 16, No. 4, pp.277-302.

Biographical notes: William Leiss is a Fellow and past President (1999-2001) of the Royal Society of Canada and an Officer in the Order of Canada. From 1999 to 2004, he held the NSERC/SSHRC Research Chair in Risk Communication and Public Policy in the Haskayne School of Business, 
University of Calgary. From 1994 to 1999, he held the Eco-Research Chair in Environmental Policy at Queen's University, Kingston, Ontario. His earlier academic positions were in political science (Regina, York), sociology (Toronto), environmental studies (York), and communication (Simon Fraser). At Simon Fraser, he was also Vice President, Research. He is author, collaborator or editor of 15 books and numerous articles and reports, and for the past 20 years, he has been a frequent consultant to government agencies and the private sector on risk management issues.

Margit Westphal was a Risk Analyst at the McLaughlin Centre for Population Health Risk Assessment at the University of Ottawa from 2008-2016. Her academic background includes a PhD in Medical Sciences from the McMaster University, a Master's in Clinical Biochemistry from the University of Toronto, and a Master's certificate in Population Health Risk Assessment and Management from the University of Ottawa. Her current focus is on health risk issues related to chemical toxicity testing and prion diseases.

Michael G. Tyshenko is a Research Associate at the University of Ottawa. He specialises in interdisciplinary studies combining science, health policy, communication, risk management and impacts on society. Research areas include: emerging health risk issues, eHealth-mHealth development, biotechnology, zoonotic disease management and burden of disease studies.

Maxine C. Croteau is a former Post-Doctoral Fellow in Risk Sciences at the McLaughlin Centre for Population Health Risk Assessment. Her academic background includes $\mathrm{PhD}$ in Biology with specialisation in Chemical and Environmental Toxicology from the University of Ottawa, a Post-Doctoral Fellow Academic Program Certificate in Communications and a Residency in the Science Communications Program at the Banff Centre. She has worked as a toxicologist for Health Canada's Healthy Environments and Consumer Safety Branch since 2011.

Tamer Oraby works at the University of Texas Rio Grande Valley as a tenure-track Assistant Professor. He is working on mathematical epidemiology. He has 13 publications in reputable journals like Scientific Reports, the Lancet, Proceedings of the Royal Society B, Mathematical Biosciences and Engineering, Journal of Toxicology and Environmental Health and Journal of Theoretical Biology.

Wiktor (Vic) Adamowicz is the Vice Dean in the Faculty of Agricultural, Life and Environmental Sciences and a Distinguished University Professor in the Department of Resource Economics and Environmental Sociology, Faculty of Agricultural, Life and Environmental Sciences, University of Alberta. His research has focused on the economic valuation of environmental amenities and ecosystem services and the incorporation of environmental values into economic analysis - with applications to forestry, water quality, air quality, endangered species and agriculture. His research also involves the analysis of choice behaviour with applications to food demand, recreation, and environmental quality.

Ellen Goddard is Professor and Cooperative Chair in Agricultural Marketing and Business in the Faculty of Agriculture, Life and Environmental Sciences at the University of Alberta. Her research focuses on consumer behaviour and public policy about food including responses to food safety incidents, acceptance of new technologies in food production, labelling, certification and demand for credence attributes. 
Neil R. Cashman is a neurologist-neuroscientist working in neurodegeneration and neuroimmunology. His special areas of work are the motor neuron diseases, particularly amyotrophic lateral sclerosis, and the amyloid encephalopathies, including prion illnesses and Alzheimer's disease. He is a Professor of Medicine at the University of British Columbia, where he holds the Canada Research Chair in Neurodegeneration and Protein Misfolding Diseases. He is Founder and Chief Scientific Officer of ProMIS Neurosciences in Toronto. Special honours include the Jonas Salk Prize for 'a lifetime of outstanding contributions to basic biomedical research', his Tier 1 Canada Research Chair in at the UBC (2005-2018), election to the Canadian Academy of Health Sciences in 2008, and Genome BC award for Scientific Excellence in 2012.

Shalu Darshan works at the McLaughlin Centre for Population Health Risk Assessment, University of Ottawa. Her academic background includes a $\mathrm{PhD}$ in Chemistry and interdisciplinary training in population health risk management. Her research interests include risk management and policy of prion diseases and chemical toxicology. She has served as a Guest Editor for over ten special issues in peer reviewed journals, such as the Journal of Toxicology and Environmental Health (JTEH), International Journal of Risk Assessment and Management (IJRAM) and Neurotoxicology.

Daniel Krewski is a Professor in the School of Epidemiology, Public Health and Preventive Medicine at the University of Ottawa, where he also serves as Scientific Director of the McLaughlin Centre for Population Health Risk Assessment. He also serves as Chief Risk Scientist for Risk Sciences International, which works in partnership with the University of Ottawa. His research interests include epidemiology, biostatistics, risk assessment, and risk management. He is a fellow of the Society for Risk Analysis, the American Statistical Association, and a National Affiliate of the US National Academy of Sciences. He holds the Natural Sciences and Engineering Research Council of Canada Chair in Risk Science at the University of Ottawa.

\section{Introduction}

"We feel that the current program that we have had in place for chronic wasting disease ... is not effective in achieving its goals", said Penny Greenwood, national manager of domestic disease control for the Canadian Food Inspection Agency. "This is a disease that is now established in wildlife, and when you have a disease that is established in a wildlife reservoir, it is always extremely difficult to eliminate it. We have to realize that we may not be able to eradicate this disease currently from Canada, given that we don't have any effective tools, so we may be looking at switching from eradication to control", said Ms. Greenwood. (Canadian Press, 2013)

This statement appears in a news report from mid-June 2013, and it reflects well the severe challenges faced by risk managers, in both Canada and the USA, in their effort to find an effective risk management response to chronic wasting disease (CWD). CWD is a fatal neurodegenerative disease of various species of animals in the cervid family, which includes deer, elk, reindeer, caribou and moose. The disease is most prevalent among deer species, affecting in particular mule deer, but also black-tailed deer and white-tailed deer. CWD belongs to a group of related neurodegenerative diseases called transmissible 
spongiform encephalopathies (TSEs), a group which also includes bovine spongiform encephalopathy (BSE), scrapie and variant Creutzfeldt-Jakob disease (for recent review see Haley and Hoover, 2015). CWD is prevalent in both farmed and wild cervids and is considered to be one of the most contagious forms of TSE known (Miller and Williams, 2002).

\subsection{CWD monitoring}

Disease surveillance in North America has provided some qualitative assessments of the overall risk of CWD in Canada and the USA. A combined map of disease distribution for both wild and captive cervids in North America has been reproduced in Figure 1 (USGS, 2016). As of April 2016, CWD has been detected in many US states (23 states as of September 2016) and two Canadian provinces (CWDA, 2016a). The first case of CWD detected outside of North America was in a seven-year-old male elk exported from a Saskatchewan farm to South Korea in 1997 (Sohn et al., 2002). The European Commission has also established surveillance, sampling and testing protocol for CWD in cervids (Andreoletti et al., 2010). The first case of CWD diagnosed in Europe was in a female reindeer in March 2016 (Rangifer tarandus tarandus) by the Norwegian Institute for Nature Research (CWDA, 2016b).

Figure 1 Geographical distribution of CWD in North America (see online version for colours)

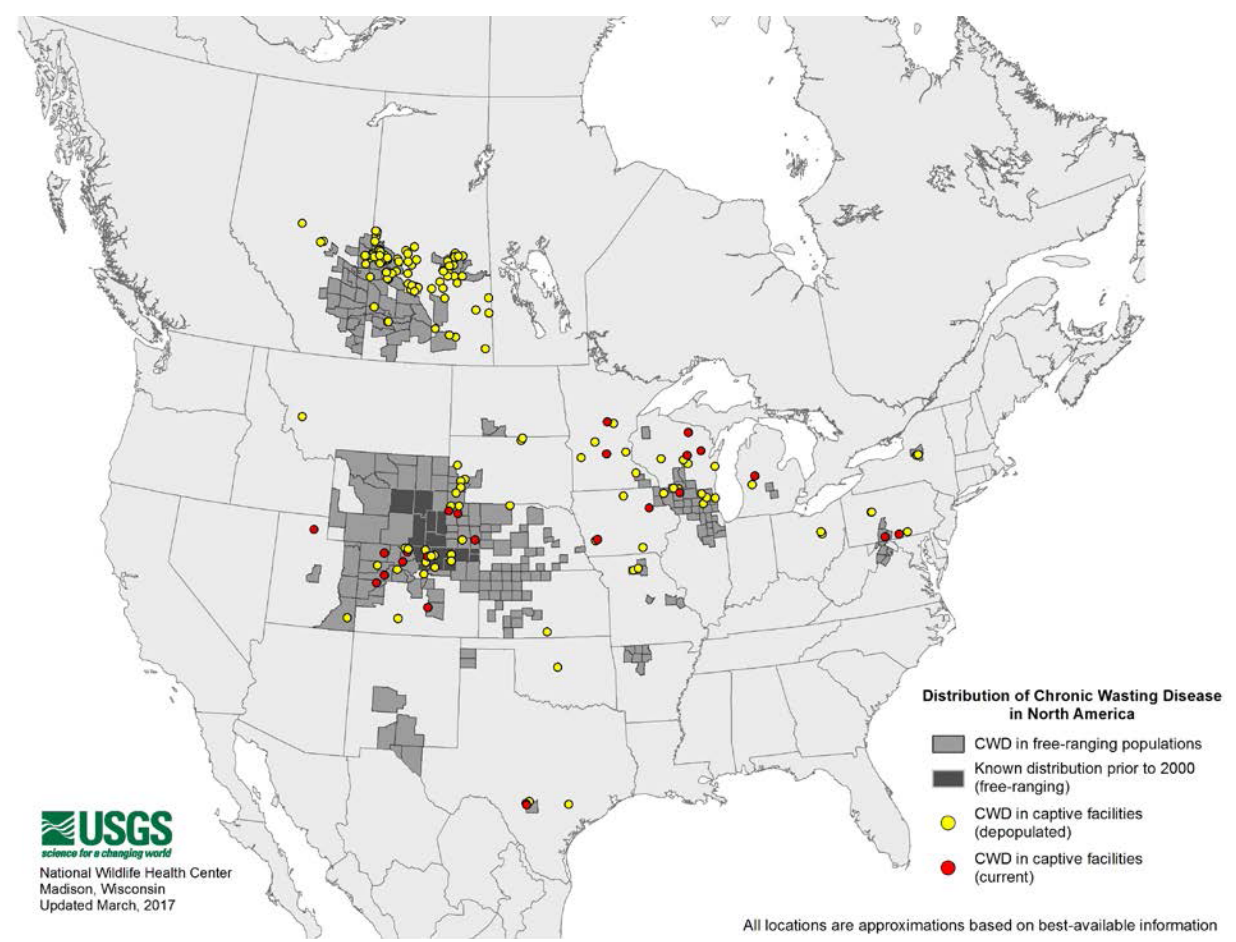

Source: USGS (2016) (courtesy of the US Geological Survey), http://www.nwhc.usgs.gov/images/cwd/cwd_map.jpg 


\subsubsection{The USA}

The first identification of CWD as a clinical disease anywhere in the world occurred in the USA at a state research facility in Fort Collins, Colorado in 1967, and the first case in a wild cervid (an elk) was found in 1981, also in Colorado. The US Centers for Disease Control and Prevention have prepared a detailed county-by-county list showing the distribution of CWD in wild deer and elk cervids in that country. As of January 2016, 21 US states have positive CWD cases in the wild and the disease is expected to continue to spread (CDC, 2016). The US Federal Government has concentrated on the development of increasingly precise surveillance methods for CWD (USGS, 2012), and states have sought to develop 'CWD management response plans' (examples are Wisconsin Department of Natural Resources, 2010; Michigan Department of Natural Resources, 2012; Illinois Department of Natural Resources, 2014; Texas Parks and Wildlife, 2016).

As of 30 September 2015, CWD has been confirmed in 16 States among farmed cervids; a total of 70 herds have been affected (USAHA, 2015). The US Department of Agriculture, Animal and Plant Health Inspection Service (APHIS) has focused on the National CWD Herd Certification Program (HCP) as a national approach to minimise CWD spread in domestic cervid herd populations by implementing national herd certification standards, such as fencing, regular inventories, individual animal IDs, and CWD testing of all cervids that die and are over 12 months. When herds are CWD disease free for five years, the herds can then be certified and considered to be low risk for CWD. All animal movement must be within herds that are participating in the certification program. The first edition of the CWD program standards was published in 2012, with the final version published in 2014 after extensive review and stakeholder input. As of January 2015, 29 states are participating as approved states in the national CWD HCP (APHIS, 2015).

\subsubsection{Canada}

In 1996, CWD was diagnosed on a Saskatchewan elk farm. Farmed elk exported from the USA in the late 1980s were believed to be responsible for the entry of CWD into Saskatchewan (Kahn et al., 2004). The actual first case of a captive cervid displaying CWD in Canada occurred in 1978 in a mule deer at a Toronto zoo, but the case remained undiagnosed until 2006 (Dubé et al., 2006). Since 2002, CWD has been a reportable disease in Canada under the Health of Animals Act, which is under the jurisdiction of the Canadian Food Inspection Agency (CFIA). Federal regulations on CWD focus on this disease only among farmed animals, including potential transmission through deer and elk antler velvet (Angers et al., 2009), a commercial product from cervid farms. When CWD is reported on a farm it is placed under quarantine and the remaining animals are destroyed and sampled for the disease. Surveillance and tracing of all animals that came into the farm and left the farm in the 36-60 months prior to infection is important for disease containment (Kahn et al., 2004). Under this policy, the CFIA depopulated over 7,500 farmed elk and deer in Canada, at which time compensation was paid to the owners of CWD-affected farms (CFIA, 2016).

Most of the cases of CWD among farmed cervids (deer and elk) in Canada have occurred in the province of Saskatchewan. The Canadian Food Inspection Agency website (CFIA, 2016) lists a total of 77 herds of captive or farmed cervids where CWD 
has been detected for the period 1996 to 2015, including three herds in year 2016. Only two of those farmed cases occurred in Alberta, and the rest in Saskatchewan.

Federal authorities in Canada have also formulated a herd certification program to identify disease-free operations, which farm owners may choose to enter voluntarily. The provinces of British Columbia (B.C.), Alberta, Saskatchewan, Manitoba, and Ontario also require animal tracing and documentation and follow quarantine, depopulation and decontamination management policies for farmed cervids. So far B.C., Manitoba and Ontario have not reported any indigenous cases of CWD in either farmed or wild animals.

The first case of CWD found in the wild cervid population in Saskatchewan was reported in a mule deer in 2000; the first wild elk was detected in 2008, and the first moose was detected in Alberta in 2013. Saskatchewan's 'Cervid Chronic Wasting Disease (CWD) Surveillance Program' became mandatory in 2001. Surveillance of wild cervid populations in Saskatchewan from 1997 to Fall 2012 yielded a prevalence rate of under 1\%. The hunter surveillance program was discontinued in 2012. After 2012, only diagnostic samples were examined by the province and yielded a prevalence of $\sim 11 \%$ (CWHC, 2015).

In the Province of Alberta, the species at greatest risk are mule deer and white-tailed deer (only one case of CWD in a moose). The province undertakes disease surveillance and testing, based on samples submitted by hunters, and also collects farmed animal movement information. Most of the cases detected so far in the province have been concentrated in a region of southeastern Alberta on the Saskatchewan border, but as of 2014 the disease range was spreading to the northeast. There has been an increase in disease prevalence from $2.1 \%$ to $2.4 \%$ in mule deer in fall of 2015 (Alberta Environment and Parks, 2016). The impacts on hunters in the province have been varied, with some negatively affected by CWD (to the extent that they may no longer participate in the activity) and others not affected at all (Zimmer et al., 2011, 2012).

The B.C. Ministry of the Environment released its 'British Columbia Chronic Wasting Disease Risk Assessment' in May 2008 (British Columbia Ministry of the Environment, 2008). B.C. has been carrying out CWD surveillance of wild cervids since 2002; testing is focused on samples from the Peace and Kootenay Management Regions that border Alberta, since these areas were estimated to be the most likely routes of CWD introduction into the province. The assessment considered direct and indirect consequences of CWD including changes to cervid population numbers and sustainability, associated environmental changes, economic consequences (hunting and other nature-related activities), and impacts to cultural and traditional practices.

To date, Manitoba has not reported any cases of CWD. There is ongoing surveillance and the province has examined 'more than 2,300 deer and 1,400 elk carcasses, all of which have tested negative' (Government of Manitoba, 2016). The Province of Ontario released its comprehensive 'Chronic Wasting Disease Surveillance and Response Plan' in November 2005, and a similar program for farmed cervids in the following year; as of May 2016 no case of CWD in free-ranging or commercially-farmed cervids had been reported in Ontario (OMNR, 2016). (The only cases in Ontario have occurred in captive mule deer at the Toronto Zoo.) However, since the disease has been found in a number of adjacent or nearby US states, Ontario has established an annual rigorous surveillance and testing program to monitor CWD, together with a risk model that identifies high-risk areas of the province for enhanced surveillance (Rosatte et al., 2014). 
In summary, taking North America as a whole, CWD distribution has occurred in two phases (see the detailed timeline at CWDA, 2016a): During Phase I, for the first 29 years following the index case (1967-1995), the disease was found only in the two Western US states of Colorado and Wyoming; during Phase II, the next 19 years (1996-2014), the disease range expanded dramatically, reaching an additional 21 US states - extending to the northeastern and southwestern borders of the nation - and two Western Canadian provinces. The long-term trends in the geographical distribution of the disease in North America are shown in Figure 2.

Figure 2 The long-term trends in the geographical distribution of CWD in North America (see online version for colours)

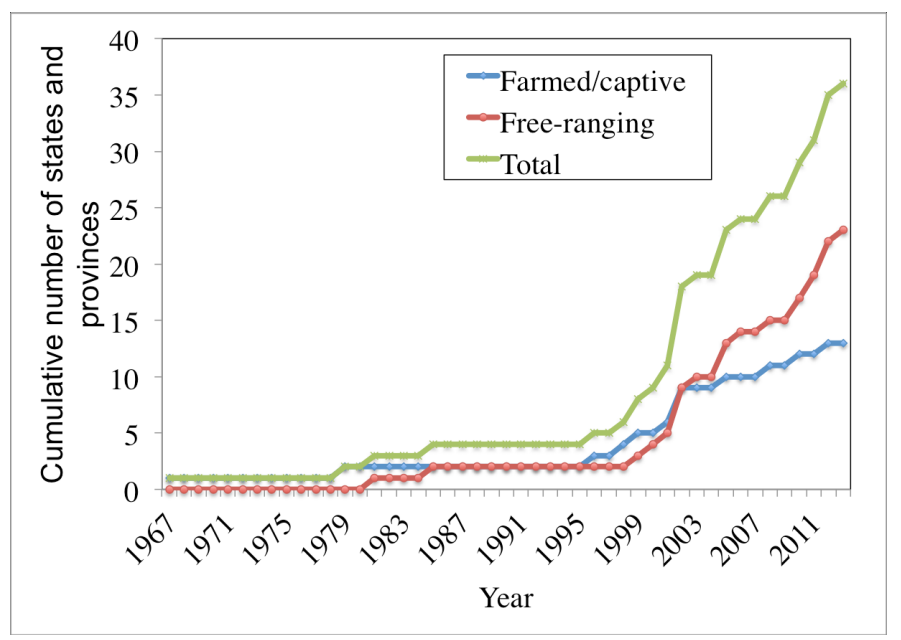

Notes: The primary source for Figure 2 is the complete timeline of CWD cases in North America found in CWDA (2016a), including both wild and captive species. In Canada, the two provinces of Saskatchewan and Alberta have cases in both wild and captive cervids. In the USA, a total of ten states also have both types: Colorado, Iowa, Minnesota, Missouri, Nebraska, New York, Pennsylvania, South Dakota, Wisconsin and Wyoming. Another ten states have reported wild cases only: Illinois, Kansas, Maryland, Ohio, New Mexico, North Dakota, Utah, Virginia, West Virginia and Texas. The final three have reported cases in captive herds only: Michigan, Montana, and Oklahoma. The total number of separate 'instances' of CWD in North America, combining wild and captive types of cervids, is therefore 37.

Source: CWDA (2016a)

\section{Hazard characteristics of CWD in North America}

Many considerations are involved in the spread of CWD, such as (for review see Haley and Hoover, 2015):

- horizontal transmission

- vertical transmission

- environmental transmission 
- genetic influence on CWD disease pathogenesis

- $\quad$ intra-species susceptibility.

Epidemiological, animal, and mutagenic studies have demonstrated a strong species barrier to CWD in humans (Kong et al., 2005; Race et al., 2009; Wilson et al., 2012); thus the probability of risk for human zoonotic infection is low (Kong et al., 2005). Research studies have also demonstrated that cattle, sheep, and goats remain uninfected after close contact with infected cervids (Belay et al., 2004). Direct intra-cerebral inoculation with mule deer CWD leads to a $38 \%$ infection rate among cattle, suggesting a natural, strong species barrier to CWD. On the other hand, intracerebral inoculation with white tailed deer CWD results in an $85 \%$ infection rate in cattle, suggesting that some cervid prion strains have more potential to cross the species barrier than others (Sigurdson, 2008).

Another cervid that is likely to acquire CWD in future is the northern caribou (Tyshenko et al., 2016), since oral exposure has resulted in disease transmission in reindeer, a close relative to the caribou (Mitchell et al., 2012). Genotype analysis has found that caribou PRNP alleles (alleles that are strongly associated with disease prevalence) are nearly identical to those of elk, moose, white-tailed deer and mule deer. In addition, caribou migratory and herd ranges over-lap with mule deer, white-tailed deer, elk and moose ranges in both Alberta and Saskatchewan (Happ et al., 2007; Li et al., 2007).

Ante-mortem CWD detection and surveillance detection methods (Haley et al., 2012; Haley and Hoover, 2015; Henderson et al., 2013; John et al., 2013) are under development. In the past, the main methods for CWD diagnosis have been immunohistochemistry or ELISA on post-mortem brain samples of deceased animals. Hunter surveillance uses these methods and results can take many weeks to obtain (Gilch et al., 2011). Ante-mortem methods such as tonsil and rectal biopsies have been used for large-scale surveillance of CWD in free range and captive cervids but with limited success (Sigurdson, 2008; Wild et al., 2002; Wolfe et al., 2007). Sampling with these tests is difficult and cumbersome in the wild (Gilch et al., 2011). The protein misfolding cyclic amplification (PMCA) assay can detect low levels of misfolded prions in tissues and body fluids (Sigurdson and Aguzzi, 2007; Johnson et al., 2012) and detects animals in the early stages of CWD pathogenesis (Daus et al., 2011; Haley et al., 2012). A high-throughput version of PMCA known as the real-time quaking induced conversion (RT-QuIC) can detect CWD prions in saliva (Henderson et al., 2013), urine (John et al., 2013) and blood (Elder et al., 2013) in asymptomatic animals. However this is still a lengthy and labour intensive assay to use.

\section{Risks and risk factors associated with CWD}

Based on the evolving science that characterises the nature of the hazard represented by CWD exposure and the exposure pathway analyses, as well as on the disease management challenges since the disease was first discovered, a number of risks and risk factors related to CWD have been identified [see WDNR (2010, pp.8-10) for the best short summary]: 
1 risks to wild, free-ranging cervid species, both those already bearing the disease (deer, elk and moose) as well as the other cervid species, notably caribou and reindeer, that may be susceptible to it

2 risks to farmed cervids, including potential disease interactions between farmed and wild cervids

3 the associated risks of an ongoing, broad geographical spreading of the disease across all of North America

4 risks to human health and to other domestic farmed animals, especially cattle, pigs and sheep

5 risks to the traditional lifestyle and culture of aboriginal peoples in North America

6 ecosystem risks, both direct and indirect, such as a spreading of the disease to other mammals (such as meadow voles and other rodents) and high prion persistence in the soil.

Risks to wildlife often translate to risks and impacts on different groups of people as well. Non-aboriginal hunters may be affected by CWD in wildlife from a health risk perspective, and are affected by an impairment of the enjoyment of hunting as a recreational experience. Aboriginal peoples in North America may be affected through similar impacts on their traditional use of land and wildlife. Should the disease eventually spread to reindeer and woodland caribou, impacts on aboriginal peoples and the general public will greatly increase (Mitchell et al., 2012).

Although no formal quantitative risk assessment of CWD has been performed to date, the level of at least some of these identified risks can be estimated qualitatively with a high degree of confidence, on the basis of the extensive, accumulated scientific studies of hazard and exposure. With respect to the first-mentioned risk on this list, the disease is by now well established in North America in five species of cervids, over a large geographical range in the USA and a quite restricted range in Canada (concentrated on the Saskatchewan-Alberta border). In addition, there are smaller numbers of cases in elk and very few in moose so far (for the latter, only for moose living in close proximity to diseased deer). However, there are basically no grounds for believing at this time that the disease can be eradicated, and thus it must be regarded as being endemic, with prospects for spreading gradually to new geographical areas and perhaps to other cervid species, and for increasing in prevalence in areas where it is already well established.

It is advisable to consider separately the disease dynamics in farmed cervids, taking into account the fact that it was in farmed cervids that the disease was first detected in the USA (deer and elk in the states of Colorado and Wyoming), and that it was 14 years later before the first case in a wild cervid was discovered (deer and elk, both in Colorado). The same pattern was repeated in Canada, which had its first indigenous farmed CWD case in 1996 and its first wild cervid case in 2000, both in Saskatchewan. In ten of the 16 US states and in both Canadian provinces where CWD has appeared in farmed cervids, it has also been found in wild cervids. Farming of cervids is still increasing, especially in the USA (Miller, 2012), and so this potential disease reservoir is likewise expanding. On the other hand, another ten US states have reported cases only in wild cervids and three others only in farmed cervids.

A deficiency in the risk assessment of CWD in North America to date is the failure to address adequately - through a formal quantitative assessment - the risks entailed by the 
interactions of farmed cervids with wild infected cervids, including the role of prion persistence and loading in the environment over time. For example, prions shed in to the environment could act as a source of infection from wild cervids to farmed cervids across fenced areas. On-farm CWD transmission seems to occur more often where elk or deer are at higher densities or where they congregate at man-made feed and water stations [Michigan Department of Natural Resources and Agriculture, (2007), Section 5]. The frequent escapes of farmed animals from their enclosures, the introgression of wild animals onto farms by breaching the fencing, as well as fence-line interactions between wild and farmed cervids are other potential avenues for CWD movement between animals (Fischer et al., 2011; Miller, 2012; VerCauteren et al., 2005, 2007a, 2007b, 2010).

Both the human health risk and the risk of a spreading of CWD to any domestic farm animals, including cattle, pigs and sheep, appear to range from low to very low. The human health risk, related to consumption of or exposure to infected cervid materials, may even be regarded as negligible, although there are some uncertainties in these areas noted in the scientific literature (Belay et al., 2004).

As already observed, the potential for a spreading of CWD to other cervid species, especially caribou and reindeer, and thus the associated potential for a further extensive geographical spreading of the disease, appears to range from high to very high, and perhaps up to the level of near-certainty, at least in the estimation of some experts (Oraby et al., 2016). This prospect has significant potential impacts beyond the animal species risks themselves, specifically with respect to aboriginal peoples in North America.

Given the historical dependence of northern aboriginal peoples in Canada on the threatened species, especially caribou, the consequent risks to the lifestyles and traditional cultures of these peoples is similarly high. And as mentioned above, the impacts go beyond impacts on aboriginal people. The fact that boreal caribou are listed as threatened under Canada's Species at Risk Act (SARA), as well as under provincial wildlife legislation, shows the public concern for this species. CWD impacts would be significant in terms of attempting to achieve the SARA recovery plan objectives or in terms of the cost of attempting to achieve recovered status. An assessment of public preferences for CWD control illustrates that the public is supportive of general outcomes associated with reduced CWD levels, largely arising from concerns over health of wildlife populations. Measures of support for government investments in such actions have also been estimated - a lower bound estimate is approximately $\$ 16$ per household in Alberta or $\$ 20 \mathrm{M}$ per year for a 10-year program period (Forbes, 2011).

Finally, there are large uncertainties associated with the ecosystem risks, both with respect to direct effects, especially the potential for spread to other mammalian species beyond the cervids, and to indirect or secondary effects, such as those which might follow increased disease prevalence among the cervids. In addition, the long persistence of prions in the environment and thus their accumulation over time may turn out to be a major factor in disease persistence:

High prion persistence is expected to lead to an increasing environmental pool of prions during the early phases (i.e., approximately during the first 50 years) of the epidemic. As a consequence, over this period of time, disease dynamics will become more heavily influenced by indirect transmission [via environmental contamination], which may explain some of the observed regional differences in age and sex-specific disease patterns. This suggests 
management interventions, such as culling or vaccination, will become increasingly less effective as CWD epidemics progress. (Almberg et al., 2011)

The level of long-term risk represented by these factors is difficult to estimate at the moment, and they will need to be monitored on an ongoing basis.

\section{Risk management of CWD}

In general, the development of potentially effective strategies for responding to CWD is complicated greatly by the presence of the disease in both captive (farmed) and wild (free-ranging) populations and by the modes of interaction between the two populations. For example, a well-established mode of control for infectious diseases in farmed animals is the culling and destruction of the diseased animals and their herd-mates, accompanied by various types of plans to compensate farmers for their losses. But this strategy has been developed largely for infectious diseases such as BSE in animals that do not exist in close proximity to wild populations of the same species which are also susceptible to the same disease. Where the contrary is the case, as with CWD, the disease reservoir in wild animals threatens to regularly infect and re-infect herds of farmed animals of the same species, and vice-versa, and this interaction presents a serious dilemma for the prospects of success for disease control strategies.

There is little experience to date in attempts to control or eradicate infectious diseases in wild animal populations (except for rabies), and species such as cervids that range over immense, continent-wide territories present significant challenges in this regard. At the same time, farming of captive cervids appears to be steadily growing in scale and geographical range, certainly in the USA (Miller, 2012); indeed, the "farmed deer breeding industry has been called the 'fastest growing industry in rural America' (Anderson et al., 2007)" (Fischer et al., 2011). In this context, a systematic quantitative risk assessment of the CWD disease interactions between farmed and wild cervids, which does not seem to have been carried out anywhere in North America to date, is urgently required, including more of the benefit-cost analyses relevant to the management of these interactions risks of the kind undertaken by Arnot et al. (2009).

\subsection{Studies of behavioural and attitudinal factors}

Many of the CWD risk control strategies available to public authorities depend heavily on the adequacy of awareness and voluntary participation among hunters and the public. Research on these factors is, therefore, an important dimension in understanding the challenges and options for managing the risks of CWD. For the situation in the USA, Vaske (2010) summarised much of the existing human-oriented research on CWD published to date, which was dominated by a focus on hunters and their potential behaviours. This research on hunter behaviour was undertaken at a time when CWD was a relatively unfamiliar disease within the state or region where the studies were focused. Some key characteristics of the studies were the fact that hunters did seem to understand the existence of CWD and have concerns about its continuing spread; however, at the initial low levels of prevalence of the disease few hunters felt the need to change hunting behaviour, although non-resident hunters in particular states did show greater willingness to change hunting location or stop hunting altogether. Many studies (such as Vaske and 
Lyon, 2011; Needham et al., 2006, 2007; Vaske et al., 2004) showed the importance of CWD prevalence, potential human death, perceived human health risk, presence of CWD in the state, and residency of hunters in predicting changes in hunter behaviour, which would mostly occur at high hypothetical prevalence of the disease.

Of more concern in the actual management of CWD appeared to be tension among hunters and government agencies involved in the management of the disease. Needham and Vaske (2008) showed that if hunters shared the same views on CWD with government agencies managing the disease, then there was higher trust in those agencies and this higher trust led to lower perceived personal risk from CWD. Heberlein (2004) found that the Wisconsin strategy of treating CWD 'like a fire' had reduced the effectiveness of the management strategy of significant herd reduction in Wisconsin. Cooney and Holsman (2010) found that a government strategy of controlling the disease and reducing its spread might have had more support from hunters than the attempt to eradicate the disease. Holsman et al. (2010) noted that although the majority of hunters saw CWD as something important to manage, few hunters actually increased their harvest of animals in spite of various government incentives, suggesting that hunter behaviour is unlikely to be an effective deer herd reduction management tool: "our findings call into question the efficacy of recreational hunting as a disease management tool when managers are seeking severe reductions in wildlife densities" (Other studies on hunter attitudes and behaviour involving the risks of CWD include: Gigliotti, 2004; Heberlein and Stedman, 2009; Holsman and Petchenik, 2006; Lyon and Vaske, 2010; Miller, 2003, 2004; Miller and Shelby, 2009; Needham and Vaske, 2006; Needham and Vaske, 2008; Vaske et al., 2006a, 2006b).

Relatively few studies have looked at the views of the non-hunting public on the management of CWD or the potential health risks associated with the disease. Needham and Vaske (2006) included a small sample of non-hunters in Wisconsin in their study, finding that although many respondents in both categories believed that CWD may cause disease in humans and were concerned about eating deer and elk due to CWD, hunters were more likely than non-hunters to believe that the risks of CWD had been exaggerated. Brown et al. (2006) discovered that the majority of hunters and non-hunters in New York State had heard of CWD but did not exhibit high levels of concern about the disease, potentially due to higher than average levels of trust in the agencies managing the disease. In comparative studies Goddard et al. $(2010,2011)$ conducted online surveys of Canadian (2009) and US (2010) members of the public. These surveys were conducted with the aid of market research companies using their standard national panels in each country, with the added restriction that at least $50 \%$ of the sample in each country must have consumed venison in their lifetime. The data showed that in neither country was there significant awareness of the CWD prior to the time of the surveys; moreover, even for those who had heard of CWD prior to the survey, only $41 \%$ realised that CWD affected both deer and elk. In these studies public awareness was lower in the USA than in Canada.

Survey respondents were also asked about their level of agreement with different strategies for CWD control (Myae and Goddard, 2011). Among the surveyed respondents as a whole the distribution of materials about CWD, holding public meetings, mailings, and facilitation of collection of heads for testing were all preferred strategies. Approval of culling as an acceptable strategy was much lower in the people with no experience of eating venison than among the people who had such experience, many of whom were also hunters. This study also found that older respondents, people who ate venison from 
hunted animals more frequently, and people who believe that eating venison will cause a CWD-type infection in humans were more positive about culling of animals in both Canada and the USA. In Canada, males and people with higher education were more supportive of culling while people living in rural areas were less supportive of culling. It is worth noting that Lischka et al. (2010) found high levels of support by hunters and the non-hunting public in Illinois for significant herd reduction as a management strategy in CWD-infected areas. The targeting of a geographic area where CWD had been found and thereafter had higher local media coverage suggests that public support for herd reduction or culling is higher the nearer the disease to the surveyed members of the public. However, Lischka et al. (2010) also found very high levels of support for more passive forms of management, such as educating hunters and the public, funding research about CWD, and increasing the regulation of deer and elk farms.

\section{Risk control strategies for CWD}

Thus there are a number of factors that represent major intrinsic obstacles to risk control of CWD, which provide at least a partial explanation for the failure to arrest the spread of the disease so far. The suite of disease control strategies for CWD that have been implemented will be discussed in the following pages. For some time now the situation in Canada has been described as described by the Canadian Wildlife Health Cooperative (CWHC, 2011a): "the ultimate objective of Canada's National CWD Control Strategy is eradication of CWD from Canada or, failing this, the tightest possible control of CWD so that it does not spread to new geographic areas or new species, and so that its environmental, economic, social and public health impacts are minimized". This is a word-for-word repetition of the objective that was first announced by the same organisation in 2005. The wording is interesting, of course, for its clear recognition, even then, that eradication of CWD was unlikely to be a feasible objective, and that the alternative of control, as defined - preventing a spread to new areas or new species - was the best outcome that could be hoped for.

As we have seen, this theme was reaffirmed by the CFIA, the federal agency with national regulatory responsibility for the disease, in the statement made by an agency official in mid-2013: "we have to realize that we may not be able to eradicate this disease currently from Canada, given that we don't have any effective tools, so we may be looking at switching from eradication to control" (Canadian Press, 2013). This is the same conclusion that the State of Wisconsin arrived at in 2010, in the course of preparing what is almost certainly the best overall document on CWD risk management strategies that currently exists (WDNR, 2010):

\footnotetext{
"We are therefore establishing the following goal for the management of CWD over the next 15 years: Minimize the area of Wisconsin where CWD occurs and the number of infected deer in the state. The currently identified geographic distribution of CWD is substantially larger than was known in 2002 and is likely increasing. Eliminating CWD from Wisconsin using the tools currently available is unlikely given the difficulty in managing CWD in free-ranging deer, magnitude of deer reductions required to significantly affect the disease, and declining legislative support. However, there is still a need to take steps to effectively manage CWD regardless of the continued challenges. Therefore, minimizing the area of the state where the disease occurs is the responsible goal to pursue. This goal does indicate a shift in our original
} 
management approach by currently accepting an area of CWD infection in southern Wisconsin, and at the same time, focusing CWD control efforts on limiting CWD to that area of the state while simultaneously controlling its intensity and distribution."

The truth of the matter is, unfortunately, that the intrinsic difficulties in disease control mentioned above raise the distinct possibility that achieving the objective of control too appears to exceed the capacity of the tools that are currently available. 'Control', as opposed to the earlier focus on 'eradication', is usually defined as seeking to prevent an increase in both disease prevalence and regional disease distribution over existing levels, as defined by response plans formulated at particular points in time. But the steady increases in both CWD prevalence and distribution in recent years, considering North America as a whole, suggests that 'control' was already known to be not working particularly well at the time when it was promulgated as a 'new' risk management objective (replacing eradication). And it is not at all clear what other strategy might be devised to succeed that of control.

These considerations leave open the key question of what are the realistic objectives for the risk mitigation of CWD that are actually possible or feasible in the coming years. We may be better able to comment on this key question after reviewing the suite of disease control strategies that have been attempted to date. In this context, readers may wish to consult the complete set of 'Chronic Wasting Disease and Cervidae Regulations in North America', arranged by US state and Canadian province, that is available at CWDA, 2016c (see also CWHC, 2011b). Only a short summary of widely used measures for wild and farmed cervids is provided here, which will be compared with the results of an expert elicitation exercise in each case.

\subsection{Wild (free-ranging) cervids}

Various selections of the following strategies have been implemented for wild (free-ranging) cervids in different US states and in the provinces of Alberta and Saskatchewan:

- Notification (mostly voluntary, mandatory in specified high-risk areas): hunters are encouraged to report sick animals and to submit heads of animals for testing.

- State and provincial authorities provide public freezers at designated locations for hunters to deposit cervid animal heads for testing (in Canada, B.C., Saskatchewan, and Ontario, e.g., OMNR, 2016).

- Surveillance, monitoring and testing: states and provinces compile statistics on numbers of animals reported and tested and the numbers of positive results. Evidence of increases over time in regional disease prevalence can be used to implement enhanced surveillance and special monitoring programs in particular areas which represent possible new foci for the disease.

- Herd reduction: extending hunting seasons in areas with high concentrations of animals (which facilitates disease transmission), and developing special culling programs, such as culling of deer in localised areas of high disease prevalence or along the leading edge of a known new outbreak of the disease, and culling of sick animals by sharpshooters outside of the regular hunting seasons (e.g., IDNR, 2014). 
- Hunter control: for example, prohibitions against moving high-risk parts of carcasses out of areas where CWD is established, and regulations on disposal of carcass parts.

- Recommendations for hunter precautions to follow when field-dressing an animal, e.g., wear rubber gloves, minimise handling of brain, eye, or spinal tissues, and avoid cutting through the spine (Government of Manitoba, 2016).

- Feeding and baiting ban: prohibiting the dispersal of feed to attract wild animals, because it encourages close proximity and thus raises the potential for disease transmission.

- Transport ban: banning the movement of hunter-harvested carcasses across jurisdictional lines, and requiring a permit for the movement of live Cervidae across jurisdictional boundaries.

- Opinion survey and outreach and communication programs: used to increase citizen familiarity with CWD and awareness of the importance of controlling the disease.

- Applied Research Programs: For example, modelling to assess changes in spatial distribution and prevalence of disease (for assessing the effectiveness of management actions), and improved disinfection and decontamination protocols (Nobert et al., 2016; Potapov et al., 2016; Uehlinger et al., 2016).

An expert elicitation exercise resulted in set of risk control measures for wild cervids, ranked in order of importance (see Figure 3).

Figure 3 Weighted averages of the ratings for the 15 control measures of CWD in the wild cervids

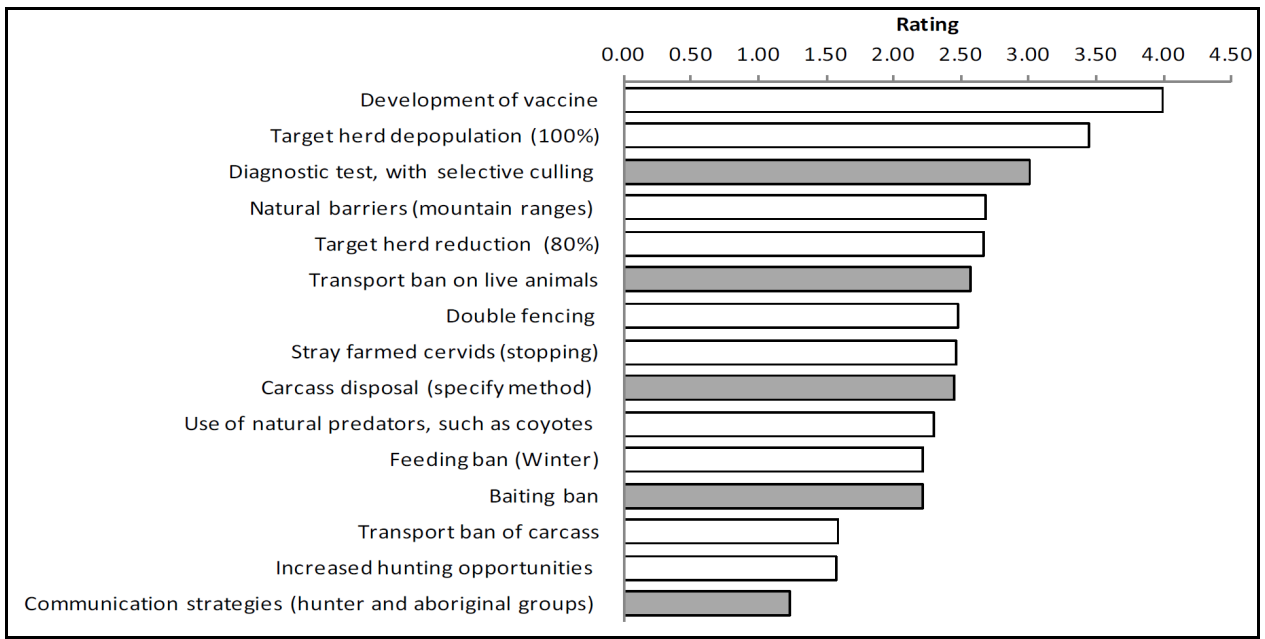

Source: Oraby et al. (2016, Figure 5)

\subsection{Farmed cervids}

The following strategies have been implemented for farmed cervids in different US states and in the provinces of Alberta and Saskatchewan: 
- $\quad$ in general, many jurisdictions have extensive sets of rules and specifications for farmed cervids - see, e.g., the combined federal and state rules for deer farmers in Wisconsin, especially Subchapter VII of the relevant statute (WDNR, 2015a)

- $\quad$ registration and voluntary certification of cervid farms (e.g., APHIS, 2015)

- notification of diseased animals (mandatory for operators of cervid farms)

- $\quad$ protocols for the reporting and recovery or destruction of escaped animals and best management practices, including provision for recovery paddocks

- $\quad$ surveillance/testing: testing programs and protocols designed to detect, monitor, and control diseases, with participation and reporting mandatory for operators of cervid farms

- cervid identification (ear tags) and traceability requirements for tracking of movements

- regulation of movement between farms, including mandatory permits

- import regulation: government permit required for movement between countries

- transport regulation: regulating or banning the movement of captive live animals across intra-country jurisdictional lines

- herd depopulation: destruction of entire herds in which diseased animals are found, followed by securing of the affected area (maintenance of fencing to prevent ingress of wild animals) and application of decontamination protocols

- facility management: regulating fencing for captive herds, including double-fencing and electric fencing (Fischer et al., 2011).

Figure 4 Weighted averages of the ratings for the 14 control measures of CWD in the farmed cervids

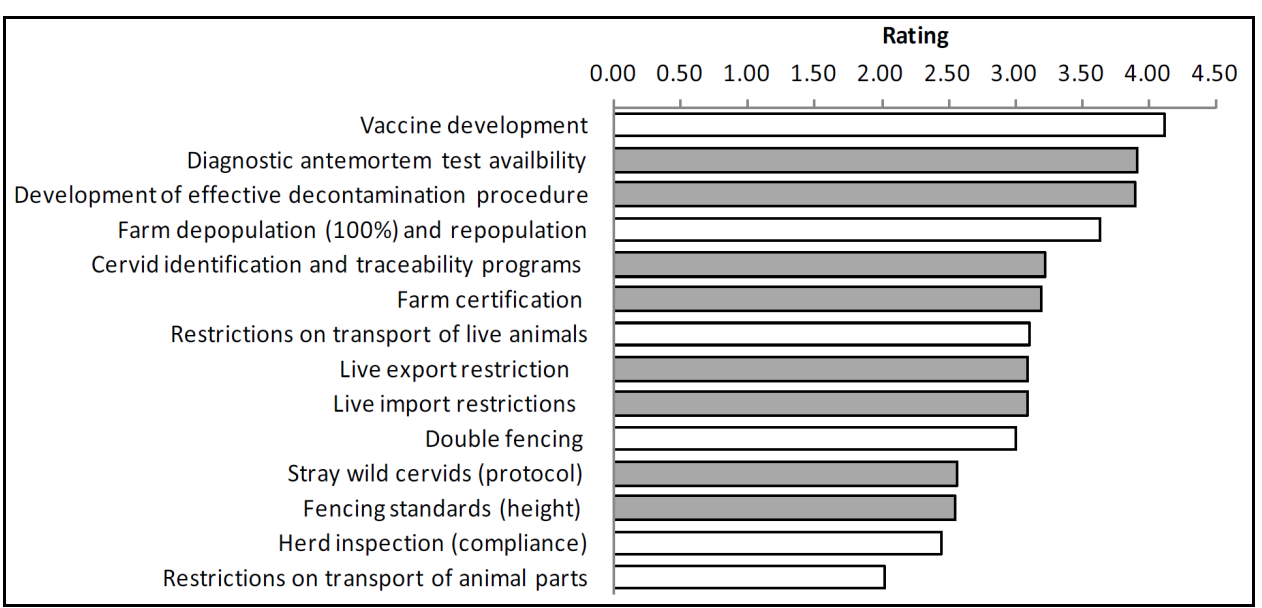

Source: $\quad$ Oraby et al. (2016, Figure 6) 
The ongoing surveillance and random testing protocols, together with herd depopulation and facility decontamination protocols, are the most common strategies in all jurisdictions for the attempt to control CWD in farmed cervids.

An expert elicitation exercise resulted in set of risk control measures for farmed cervids, ranked in order of importance (see Figure 4).

\section{Conclusions}

As noted above, taking North America as a whole, CWD distribution has occurred in two phases (see the overall timeline at CWDA, 2016b). During phase 1, for the first 29 years following the index case (1967-1995), the disease was found only in the two Western US states of Colorado and Wyoming; during phase 2, the next 18 years (1996-2013), the disease range expanded dramatically, reaching an additional 20 US states - extending to the northeastern and southwestern borders of the nation - and two western Canadian provinces.

The extensive document (MDNRA, 2007) prepared for the State of Michigan, for example, shows the great effort that some jurisdictions have made in terms of advance planning and preemptive measures for CWD disease control (the surveillance measures in place resulted recently in the detection of the first case of CWD in a farmed cervid in that state). Some planning of this type has been under way in the USA for about three decades, and yet the seemingly inexorable spread of the disease among free-ranging cervids in geographical terms, and in terms of new cervid species, proceeds apace. In view of this simple fact, there are strong efforts under way to improve surveillance methodologies for free-ranging cervids (USGS, 2012).

There does not seem to be a comprehensive database of disease prevalence across all affected regions of the two countries. (Prevalence is estimated as a percentage of infected cases in the population sampled. So far as can be determined, there are no overall estimates of prevalence in farmed cervid populations). Examination of reported prevalence in some specific localities appears to indicate that on the whole prevalence is still relatively low; nevertheless, in general prevalence does seem to be increasing steadily in areas where the disease is well established. Various estimates of prevalence range from as low as $<1 \%$ (for example, among some species in the two affected Canadian provinces), to others in the $1 \%-5 \%$ range, and to some others at much higher levels. In regions of Wyoming, prevalence in mule deer "has grown from $\sim 11 \%$ to $\sim 36 \%$ from 1997-2007, with local annual prevalence growth rates in excess of 1.15\%" (Almberg et al., 2011). In the state of Wisconsin, the current figures in certain areas are quite high and the rate of increase is disturbing (Bergquist, 2014; WDNR, 2015b):

\begin{abstract}
"Since 2002, chronic wasting disease (CWD) prevalence within our western monitoring area has shown an overall increasing trend in all sex and age classes. During the past 13 years, the trend in prevalence in adult males has risen from 8-10 percent to over 25 percent, and in adult females from about 3-4 percent to more than 10 percent. During that same time, the prevalence trend in yearling males has increased from about 2 percent to about 8 percent and in yearling females from roughly 2 percent to about 7 percent."
\end{abstract}

In late 2011, this state also reported this result from the depopulation of a captive herd (WDNR, 2011): "the 80\% prevalence rate discovered on Buckhorn Flats is the highest prevalence recorded in any captive cervid operation in North America". Heberlein and 
Stedman (2009), Cooney and Holsman (2010) and Holsman et al. (2010) argue that initial attempts to control CWD in Wisconsin were less successful in reducing prevalence of the disease than they might have been with better engagement with hunters and non-hunting public in their planning and implementation. Wisconsin has a very large and densely concentrated deer population, which is known to be a factor in efficient disease transmission, and which could account for these relatively high numbers. The high prevalence $(25 \%)$ noted recently for Wisconsin includes the two counties (Dane and Iowa) where CWD was first detected among wild cervids in that state (Bergquist, 2014).

In conclusion, there are a number of trends in the evolving pattern of CWD in North America that would appear to justify some new initiatives in risk management decision making for this issue. There is a pervasive sense among some risk managers at the state and provincial levels that the major disease control strategies selected to date are either not working, or are proving only minimally effective in controlling the disease in specific areas. But if new initiatives are to be considered, robust methods must be used in order to set priorities among risk control options, through risk-ranking and benefit-cost analyses, and to concentrate resources on the preferred strategies which emerge from such exercises.

The possibility that there may soon be an effective vaccine for CWD is very significant in this regard. Researchers have mimicked a common mode of prion infection using CWD prion inserted into an attenuated Salmonella bacterium to produce anti-prion antibodies. This vaccine is has shown some success and is under further development (Goñi et al., 2015). Another group in Canada has also developed a vaccine that is currently under clinical trials with elk (PREVENT, 2015).

Expert opinion already obtained has provided some other candidate strategies for consideration:
"Policies aimed at reducing the presence of the infectious CWD agent in the environment (including carcass disposal and CWD positive farm depopulation), reducing deer densities (targeted culling), and reduced movement of cervids in critical areas (through the use of fencing, double fencing, or natural barriers) were considered to be effective control measures, and were ranked highly by experts for both wild and farmed cervids." (Oraby et al., 2016)

In addition, further research and innovation in prion disinfection and decontamination technologies would appear to be a high priority. Finally, using genetic information as a way to improve risk management is another possible initiative: Geospatial maps with genetic data taken from ongoing CWD surveillance could show geographical areas of susceptibility or resistance to CWD for various cervid species, thus allowing risk managers to allocate management resources better on the basis of disease distribution.

At the broadest level, risk managers may wish to assign high priority to carrying out systematic reviews or expert elicitation exercises in two areas:

1 What risk mitigation strategies are available, now that the objective of disease eradication has been abandoned, if the objective of disease control should similarly fail?

2 What cost-effective strategies, if any, are available for further isolating populations of farmed and wild cervids if the disease interactions between these two populations should appear to be more problematic than it is considered to be at present? 
Such exercises might begin with consultations among government and academic scientific and wildlife management specialists, using established techniques for consensus building. At those sessions some consideration should be given to the advisability of preparing quantitative risk estimates for the top-ranked CWD risks, especially, and urgently, as noted earlier on the crucial issue of potential disease interactions between farmed and wild cervids. Then the results from these initial consultations should be taken out to important external stakeholders - aboriginal peoples, hunters and cervid farm operators, public-interest groups, and others - across a broad range of regional locations, reflecting the scope of the disease outbreak to date. Prior to these outreach campaigns, some effort should be put into using effective risk communication on the scientific and technical aspects of the risk management of CWD.

\section{References}

Alberta Environment and Parks (2016) Chronic Wasting Disease (CWD) Surveillance Update [online] http://aep.alberta.ca/fish-wildlife/wildlife-diseases/chronic-wasting-disease/ default.aspx (accessed 15 August 2016).

Almberg, E.S., Cross, P.C., Johnson, C.J., Heisey, D.M. and Richards, B.J. (2011) 'Modeling routes of chronic wasting disease transmission: environmental prion persistence promotes deer population decline and extinction', PLoS One, Vol. 6, No. 5, p.e19896.

Anderson, D.P., Frosch, B.J. and Outlaw, J.L. (2007) Economic Impact of the Texas Deer Breeding Industry, APFC Research Report 07-3, Texas A\&M University, Agricultural and Food Policy Center, College Station, Texas, USA.

Andreoletti, O., Berkvens, D., Ducrot, C., Gavier-Widen, D., Griffin, J., Hope, J. and Vanopdenbosch, E. (2010) 'Scientific opinion on the results of the EU survey for chronic wasting disease (CWD) in cervids', EFSA Journal, Vol. 8, No. 10, pp.1-29.

Angers, R., Seward, T.S., Napier, D., Green, M., Hoover, E., Spraker, T., O'Rourke, K., Balachandran, A. and Telling, G.C. (2009) 'Chronic wasting disease in elk antler velvet', Emerging Infectious Diseases, Vol. 15, No. 5, pp.696-703.

Animal and Plant Health Inspection Service, United States Department of Agriculture (APHIS) (2015) Voluntary National CWD Herd Certification Program [online] https://www.aphis.usda.gov/aphis/ourfocus/animalhealth/animal-diseaseinformation/ sa_alternate_livestock/sa_cervid_health/sa_cwd/ct_farmed (accessed 15 July 2016).

Arnot, C., Latte, E., Unterschultz, J. and Adamowicz, V. (2009) 'Chronic wasting disease (CWD) potential economic impact on cervid farming in Alberta', Journal of Toxicology and Environmental Health, Part A, Vol. 72, Nos. 17-18, pp.1014-1017.

Belay, E.D., Maddox, R.A., Williams, E.S., Miller, M.W., Gambetti, P. and Schonberger, L.B. (2004) 'Chronic wasting disease and potential transmission to humans', Emerging Infectious Diseases, Vol. 10, No. 6, pp.977-984.

Bergquist, L. (2014) ' 1 in 4 deer in Iowa, Western Dane Counties [Wisconsin] has chronic wasting disease', Milwaukee Wisconsin Journal Sentinel [online] http://www.jsonline.com/news/ wisconsin/1-in-4-deer-in-dane-iowa-counties-has-chronic-wasting-disease-b99213273z1247165301.html\#ixzz2uQeiljKe (accessed 15 August 2016).

British Columbia Ministry of the Environment (2008) British Columbia Chronic Wasting Disease Risk Assessment, by J. Parmley, C. Himsworth and L. Nogueira-Borden [online] http://www2.gov.bc.ca/assets/gov/environment/plants-animals-andecosystems/wildlifewildlife-habitat/wildlife-health/wildlife-healthdocuments/bc_cwd_riskassess061008.pdf (accessed 15 August 2016).

Brown, T.L., Decker, D.J., Major, J.T., Curtis, P.D., Shanahan, J.E., and Siemer, W.F. (2006) 'Hunters' and other citizens' reactions to discovery of CWD in central New York', Human Dimensions of Wildlife, Vol. 11, No. 3, pp.203-214. 
Canadian Food Inspection Agency (CFIA) (2016) Chronic Wasting Disease (CWD) of Deer and Elk [online] http://www.inspection.gc.ca/animals/terrestrialanimals/diseases/reportable/cwd/ eng/1330143462380/1330143991594 (accessed 15 August 2016).

Canadian Press (2013) Ottawa Revises Strategy for Chronic Wasting Disease, by J. Cotter [online] http://www.theglobeandmail.com/news/national/ottawa-revises-strategy-for-chronicwastingdisease/article12593366/ (accessed 15 August 2016).

Canadian Wildlife Health Cooperative (CWHC) (2011a) A Proposal for Canada's National Chronic Wasting Disease Control Strategy [online] http://www.cwhcresf.ca/docs/ technical_reports/A_Proposal_for_a_National_CWD_Control_Strategy_2011_final.pdf (accessed 15 August 2016).

Canadian Wildlife Health Cooperative (CWHC) (2011b) Management of CWD in Canada: Workshop Summary [online] http://www.cwhercsf.ca/docs/technical_reports/CWD Workshop_Summary_February_910_2011_Edmonton_revised_20110516.pdf ${ }^{-}$(accessed 15 August 2016).

Canadian Wildlife Health Cooperative (CWHC) (2015) CWHC Reports: Chronic Wasting Disease Testing in Saskatchewan [online] http://www.cwhc-rcsf.ca/surveillance_data_cwd.php (accessed 15 August 2016).

Centers for Disease Control and Prevention (CDC) (2016) Chronic Wasting Disease (CWD): Occurrence [online] http://www.cdc.gov/prions/cwd/occurrence.html (accessed 15 August 2016).

Chronic Wasting Disease Alliance (CWDA) (2016a) Chronic Wasting Disease Timeline [online] http://cwd-info.org/timeline/ (accessed 15 May 2016).

Chronic Wasting Disease Alliance (CWDA) (2016b) The First Detection of Chronic Wasting Disease (CWD) in Europe [online] http://cwd-info.org/the-first-detection-of-chronic-wastingdisease-cwdin-europe/ (accessed 15 August 2016).

Chronic Wasting Disease Alliance (CWDA) (2016c) State News and Information [online] http://www.cwd-info.org/index.php/fuseaction/policy.regulationsMap (accessed 15 August 2016).

Cooney, E.E. and Holsman, R.H. (2010) 'Influences on hunter support for deer herd reduction as a chronic wasting disease (CWD) management strategy', Human Dimensions of Wildlife, Vol. 15, No. 3, pp.194-207.

Daus, M.L., Breyer, J., Wagenfuehr, K., Wemheuer, W.M., Thomzig, A., Schulz-Schaeffer, W.J. and Beekes, M. (2011) 'Presence and seeding activity of pathological prion protein (PrP(TSE)) in skeletal muscles of white-tailed deer infected with chronic wasting disease', PLoS One, Vol. 6, No. 4, p.e18345.

Dubé, C., Mehren, K.G., Barker, I.K., Peart, B.L. and Balachandran, A. (2006) 'Retrospective investigation of chronic wasting disease of cervids at the Toronto Zoo, 1973-2003', The Canadian Veterinary Journal, Vol. 47, No. 12, pp.1185-1193.

Elder, A.M., Henderson, D.M., Nalls, A.V., Wilham, J.M., Caughey, B.W., Hoover, E.A., Kincaid, A.E., Bartz, J.C. and Mathiason, C.K. (2013) 'In vitro detection of prionemia in TSE-infected cervids and hamsters', PLoS One, Vol. 8, No. 11, p.e80203.

Fischer, J.W., Phillips, G.E., Baasch, D.M., Lavelle, M.J. and VerCauteren, K.C. (2011) 'Modifying elk (Cervus elaphus) behavior with electric fencing at established fence-lines to reduce disease transmission potential', Wildlife Society Bulletin, Vol. 35, No. 1, pp.9-14.

Forbes, K. (2011) What Economic Value do Albertans Place on Containing Chronic Wasting Disease?, MSc thesis, Agricultural and Resource Economics, University of Alberta.

Gigliotti, L.M. (2004) 'Hunters' concerns about chronic wasting disease in South Dakota', Human Dimensions of Wildlife, Vol. 9, No. 3, pp.233-235.

Gilch, S., Chitoor, N., Taguchi, Y., Stuart, M., Jewell, J.E. and Schatzl, H.M. (2011) 'Chronic wasting disease', Top. Curr. Chem., Vol. 305, No. 1, pp.51-78.

Goddard, E., Aubeeluck, A., Muringai, V. and Adamowicz, W. (2010) 'Canadian public awareness of and concerns about chronic wasting disease', PrioNet Annual Meeting, 9 March, Ottawa. 
Goddard, E., Myae, A.C., Muringai, V. and Adamowicz, W. (2011) 'Canadian and American public awareness of and concerns about chronic wasting disease', APRI/PrioNet Workshop on Management of CWD in Canada, 9-10 February, Edmonton.

Goñi, F., Mathiason, C.K., Yim, L., Wong, K., Hayes-Klug, J., Nalls, A., Peyser, D., Estevez, V., Denkers, N., Xu, J. and Osborn, D.A. (2015) 'Mucosal immunization with an attenuated Salmonella vaccine partially protects white-tailed deer from chronic wasting disease', Vaccine, Vol. 33, No. 5, pp.726-733.

Government of Manitoba, Ministry of Conservation (2016) Chronic Wasting Disease [online] http://www.gov.mb.ca/conservation/wildlife/disease/cwd.html (accessed 15 August 2016).

Haley, N.J. and Hoover, E.A. (2015) 'Chronic wasting disease of cervids: current knowledge and future perspectives', Annual Review of Animal Biosciences, Vol. 3, No. 1, pp.305-325.

Haley, N.J., Mathiason, C.K., Carver, S., Telling, G.C., Zabel, M.D. and Hoover, E.A. (2012) 'Sensitivity of protein misfolding cyclic amplification versus immunohistochemistry in antemortem detection of chronic wasting disease', Journal of General Virology, Vol. 93, No. 5, pp.1141-1150.

Happ, G.M., Huson, H.J., Beckmen, K.B. and Kennedy, L.J. (2007) 'Prion protein genes in caribou from Alaska', Journal of Wildlife Diseases, Vol. 43, No. 2, pp.224-228.

Heberlein, T.A. (2004) 'Fire in the Sistine Chapel: how Wisconsin responded to chronic wasting disease', Human Dimensions of Wildlife: An International Journal, Vol. 9, No. 3, pp.165-179.

Heberlein, T.A. and Stedman, R.C. (2009) 'Socially amplified risk: attitude and behavior change in response to CWD in Wisconsin deer', Human Dimensions of Wildlife, Vol. 14, No. 5, pp.326-340.

Henderson, D.M., Manca, M., Haley, N.J., Denkers, N.D., Nalls, A.V., Mathiason, C.K., Caughey, B. and Hoover, E.A. (2013) 'Rapid antemortem detection of CWD prions in deer saliva', PLoS One, Vol. 8, No. 9, p.e74377.

Holsman, R.H. and Petchenik, J. (2006) 'Predicting deer hunter harvest behavior in Wisconsin's chronic wasting disease eradication zone', Human Dimensions of Wildlife, Vol. 11, No. 3, pp.177-189.

Holsman, R.H., Petchenik, J. and Cooney, E.E. (2010) 'CWD after 'the fire': six reasons why hunters resisted Wisconsin's eradication effort', Human Dimensions of Wildlife, Vol. 15, No. 3, pp.180-193.

Illinois Department of Natural Resources (2014) Illinois 2013-2014 Chronic Wasting Disease Surveillance and Management Report [online] http://www.dnr.illinois.gov/programs/ CWD/Documents/CWDAnnualReport20132014.pdf (accessed 15 August 2016).

John, T.R., Schatzl, H.M. and Gilch, S. (2013) 'Early detection of chronic wasting disease prions in urine of pre-symptomatic deer by real-time quaking-induced conversion assay', Prion, Vol. 7, No. 3, pp.253-258.

Johnson, C.J., Aiken, J.M., McKenzie, D., Samuel, M.D. and Pedersen, J.A. (2012) 'Highly efficient amplification of chronic wasting disease agent by protein misfolding cyclic amplification with beads (PMCAb)', PLoS One, Vol. 7, No. 4, p.e35383.

Kahn, S., Dubé, C., Bates, L. and Balachandran, A. (2004) 'Chronic wasting disease in Canada: Part 1', Canadian Veterinary Journal, Vol. 45, No. 5, pp.397-404.

Kong, Q., Huang, S., Zou, W., Vanegas, D., Wang, M., Wu, D., Yuan, J., Zheng, M., Bai, H., Deng, H., Chen, K., Jenny, A.L., O’Rourke, K., Belay, E.D., Schonberger, L.B., Petersen, R.B., Sy, M.S., Chen, S.G. and Gambetti, P. (2005) 'Chronic wasting disease of elk: transmissibility to humans examined by transgenic mouse models', Journal of Neuroscience, Vol. 25, No. 35, pp.7944-7949.

Li, L., Coulthart, M.B., Balachandran, A., Chakrabartty, A. and Cashman, N.R. (2007) 'Species barriers for chronic wasting disease by in vitro conversion of prion protein', Biochemical and Biophysical Research Communications, Vol. 364, No. 4, pp.796-800. 
Lischka, S.A., Shelton, P. and Buhnerkempe, J. (2010) 'Support for chronic wasting disease management among residents of the infected area in Illinois', Human Dimensions of Wildlife, Vol. 15, No. 1, pp.229-232.

Lyon, K.M. and Vaske, J. (2010) 'Predicting hunting participation in response to chronic wasting disease in four states', Human Dimensions of Wildlife, Vol. 15, No. 3, pp.208-220.

Michigan Department of Natural Resources (2012) Michigan Surveillance and Response Plan for Chronic Wasting Disease (CWD) of Free-Ranging and Privately-Owned Cervids [online] $\mathrm{http} / / /$ igan.gov/documents/emergingdiseases/CWDContingencyPlan_2012Update_FinalDraft_ 391020_7.pdf (accessed 15 August 2016).

Michigan Department of Natural Resources and Agriculture (2007) A Systematic Review of Michigan's Policy for CWD Prevention, Detection and Control, Prepared by J. Ducrocq et al., Centre for Coastal Health, August, 172pp.

Miller, C.A. (2003) 'Hunter perceptions and behaviors related to chronic wasting disease in Northern Illinois', Human Dimensions of Wildlife, Vol. 8, No. 3, pp.229-230.

Miller, C.A. (2004) 'Deer hunter participation and chronic wasting disease in Illinois: an assessment at time zero', Human Dimensions of Wildlife, Vol. 9, No. 3, pp.237-239.

Miller, C.A. and Shelby, L.B. (2009) 'Hunters' general disease risk sensitivity and behaviors associated with chronic wasting disease', Human Dimensions of Wildlife, Vol. 14, No. 2, pp.33-141.

Miller, J.E. (2012) A Growing Threat: How deer breeding could put public trust wildlife at risk. U.S. Fish and Wildlife Service: The Wildlife Professional, Winter, pp.22-27 [online] http://chronicwasting-disease.blogspot.ca/2012/12/a-growing-threat-how-deer-breeding.html (accessed 5 September 2016).

Miller, M.W. and Williams, E.S. (2002) 'Detection of PrP (CWD) in mule deer by immunohistochemistry of lymphoid tissues', Veterinary Record, Vol. 151, No. 20, pp.610-612.

Mitchell, G.B., Sigurdson, C.J., O’Rourke, K.I., Algire, J., Harrington, N.P., Walther, I., Spraker, T.R. and Balachandran, A. (2012) 'Experimental oral transmission of chronic wasting disease to reindeer (Rangifer tarandus tarandus)', PLoS One, Vol. 7, No. 6, p.e39055.

Myae, A.C. and Goddard, E. (2011) 'Explaining preferences for CWD management strategies', Poster presented at the PRION 2011 Congress, 16-19 May, Montreal, Quebec.

Needham, M.D. and Vaske, J.J. (2006) 'Beliefs about chronic wasting disease risks across multiple states, years, and interest groups', Human Dimensions of Wildlife, Vol. 11, No. 3, pp.215-220.

Needham, M.D. and Vaske, J.J. (2008) 'Hunter perceptions of similarity and trust in wildlife agencies and personal risk associated with chronic wasting disease', Society \& Natural Resources, Vol. 21, No. 3, pp.197-214.

Needham, M.D., Vaske, J.J. and Manfredo, M.J. (2006) 'State and residency differences in hunters' responses to chronic wasting disease', Human Dimensions of Wildlife, Vol. 11, No. 3, pp.159-176.

Needham, M.D., Vaske, J.J., Donnelly, M.P. and Manfredo, M.J. (2007) 'Hunting specialization and its relationship to participation in response to chronic wasting disease', Journal of Leisure Research, Vol. 39, No. 3, pp.413-437.

Nobert, B.R., Merrill, E.H., Pybus, M.J., Bollinger, T.K. and Hwang, Y.T. (2016) 'Landscape connectivity predicts chronic wasting disease risk in Canada', Journal of Applied Ecology, Vol. 53, No. 1, pp.1450-1459, doi:10.1111/1365-2664.12677.

Ontario Ministry of Natural Resources (2016) Chronic Wasting Disease [online] http://www.ontario.ca/environment-and-energy/chronic-wasting-disease (accessed 16 August, 2016).

Oraby, T., Tyshenko, M.G., Westphal, M., Darshan, S., Crouteau, M.C., Aspinell, W., ElSaadany, S., Cashman, N.R. and Krewski, D. (2016) 'Using expert judgments to improve chronic wasting disease management in Canada', Journal of Toxicology and Environmental Health, Part A, Vol. 79, Nos. 16-17, pp.713-728. 
Potapov, A., Merrill, E., Pybus, M. and Lewis, M.A. (2016) 'Chronic wasting disease: transmission mechanisms and the possibility of harvest management', PloS One, Vol. 11, No. 3, p.e0151039.

PREVENT (2015) CWD Vaccine [online] http://prevent-cecr.ca/our-work/project-portfolio/ (accessed 15 August 2016).

Race, B., Meade-White, K.D., Miller, M.W., Barbian, K.D., Rubenstein, R., LaFauci, G., Cervenakova, L., Favara, C., Gardner, D., Long, D., Parnell, M., Striebel, J., Priola, S.A., Ward, A., Williams, E.S., Race, R. and Chesebro, B. (2009) 'Susceptibilities of nonhuman primates to chronic wasting disease', Emerging Infectious Diseases, Vol. 15, No. 9, pp.1366-1376.

Rosatte, R., Buchanan, T., Davies, C., Middel, K., Patterson, B., Bruce, L., Gibson, M., Bennett, K., Silver, A., Taylor, S., Stevenson, B., Donovan, B., Heydon, C., Ojkic, D. and Tapscott, B. (2014) 'Chronic wasting disease surveillance program and proactive response plan for Ontario, Canada', Canadian Wildlife Biology and Management, Vol. 3, No. 2, pp.52-68 [online] http://cwbm.ca/Issues/Vol3No2.pdf (accessed 15 August 2016).

Sigurdson, C.J. (2008) 'A prion disease of cervids: chronic wasting disease', Veterinary Research, Vol. 39, No. 4, pp.1-12.

Sigurdson, C.J. and Aguzzi, A. (2007) 'Chronic wasting disease', Biochimica et Biophysica Acta-Molecular Basis of Disease, Vol. 1772, No. 6, pp.610-618.

Sohn, H-J., Kim, J-H., Choi, K-S., Nah, J-J., Joo, Y-S., Jean, W-H., Ahn, S-W., Kim, O-K., Kim, D-Y. and Balachandran, A. (2002) 'A case of chronic wasting disease in an elk imported to Korea from Canada', Journal of Veterinary Medical Science, Vol. 64, No. 9, pp.855-858.

Texas Parks and Wildlife (2016) Chronic Wasting Disease (CWD) [online] http://www.tpwd.state.tx.us/huntwild/wild/diseases/cwd/ (accessed 15 August 2016).

Tyshenko, M.G., Oraby, T., Westphal, M., Darshan, S., Croteau, M., Aspinall, W., Elsaadany, S., Cashman, N.R. and Krewski, D. (2016) 'Expert elicitation on uncertainties associated with chronic wasting disease', Journal of Toxicology and Environmental Health, Part A, Vol. 79, Nos. 16-17, pp.729-745.

Uehlinger, F.D., Johnston, A.C., Bollinger, T.K. and Waldner, C.L. (2016) 'Systematic review of management strategies to control chronic wasting disease in wild deer populations in North America', BMC Veterinary Research, Vol. 12, No. 1, pp.173-189.

US Animal Health Association, Committee on Wildlife Diseases (USAHA) (2015) Cervid Health Program Updates [online] http://portals5.gomembers.com/Portals/6/Reports/2015/reportwd2015.pdf (accessed 15 August 2016).

US Department of the Interior, US Geological Survey (USGS) (2012) Enhanced Surveillance Strategies for Detecting and Monitoring Chronic Wasting Disease in Free-Ranging Cervids [online] http://pubs.usgs.gov/of/2012/1036/pdf/ofr2012_1036.pdf (accessed 15 August 2016).

US Department of the Interior, US Geological Survey, National Wildlife Health Centre (USGS) (2016) Chronic Wasting Disease (CWD) [online] http://www.nwhc.usgs.gov/ disease_information/chronic_wasting_disease/ (Accessed 15 August 2016).

Vaske, J.J. (2010) 'Lessons learned from human dimensions of chronic wasting disease research', Human Dimensions of Wildlife, Vol. 15, No. 3, pp.165-179.

Vaske, J.J. and Lyon, K.M. (2011) 'CWD prevalence, perceived human health risks, and state influences on deer hunting participation', Risk Analysis, Vol. 31, No. 3, pp.488-496.

Vaske, J.J., Needham, M.D., Newman, P., Manfredo, M.J. and Petchenik, J. (2006b) 'Potential for conflict index: hunters' responses to chronic wasting disease', Wildlife Society Bulletin, Vol. 34, No. 1, pp.44-50.

Vaske, J.J., Needham, M.D., Stafford, N.T., Green, K. and Petchenik, J. (2006a) 'Information sources and knowledge about chronic wasting disease in Colorado and Wisconsin', Human Dimensions of Wildlife, Vol. 11, No. 3, pp.191-202. 
Vaske, J.J., Timmons, N.R., Beaman, J. and Petchenik, J. (2004) 'Chronic wasting disease in wisconsin: hunter behavior, perceived risk, and agency trust', Human Dimensions of Wildlife, Vol. 9, No. 3, pp.193-209.

VerCauteren, K., Fischer, J., Pooler, R., Lavelle, M., and Phillips, G. (2005) 'Fence-line interactions among farmed and free-ranging cervids: preliminary results', Wildlife Damage Management Conferences - Proceedings, Paper 94 [online] http://digitalcommons.unl.edu/ cgi/viewcontent.cgi?article=1087\& context $=$ icwdm_wdmconfproc (accessed 15 August 2016).

VerCauteren, K.C., Lavelle, M.J., Seward, N.W., Fischer, J.W. and Phillips, G.E. (2007a) 'Fence-line contact between wild and farmed white-tailed deer in Colorado: potential for disease transmission', Journal of Wildlife Management, Vol. 71, No. 5, pp.1594-1602 [online] http://digitalcommons.unl.edu/cgi/viewcontent.cgi?article=1717\&context=icwdm_usdanwrc (accessed 15 August 2016).

VerCauteren, K.C., Lavelle, M.J., Seward, N.W., Fischer, J.W. and Phillips, G.E. (2007b) 'Fence-line contact between wild and farmed white-tailed deer in Michigan: potential for disease transmission', Journal of Wildlife Management, Vol. 71, No. 5, pp.1603-1606 [online] http://digitalcommons.unl.edu/cgi/viewcontent.cgi?article=1716\&context=icwdm_usdanwrc (accessed 15 August 2016).

VerCauteren, K.C., Vandeelen, T.R., Lavelle, M.J. and Hall, W.H. (2010) 'Assessment of abilities of white-tailed deer to jump fences', Journal of Wildlife Management, Vol. 74, No. 6, pp.1378-1381 [online] http://digitalcommons.unl.edu/cgi/viewcontent.cgi?article= 2340\& context $=\mathrm{icwdm}$ usdanwrc (accessed 15 August 2016).

Wild, M.A., Spraker, T.R., Sigurdson, C.J., O'Rourke, K.I. and Miller, M.W. (2002) 'Preclinical diagnosis of chronic wasting disease in captive mule deer (Odocoileus hemionus) and whitetailed deer (Odocoileus virginianus) using tonsillar biopsy', J. Gen. Virol., Vol. 83, No. 10, pp.2629-2634.

Wilson, R., Plinston, C., Hunter, N., Casalone, C., Corona, C., Tagliavini, F., Suardi, S., Ruggerone, M., Moda, F., Graziano, S., Sbriccoli, M., Cardone, F., Pocchiari, M., Ingrosso, L., Baron, T., Richt, J., Andreoletti, O., Simmons, M., Lockey, R., Manson, J.C. and Barron, R.M. (2012) 'Chronic wasting disease and atypical forms of bovine spongiform encephalopathy and scrapie are not transmissible to mice expressing wild-type levels of human prion protein', J. Gen. Virol., Vol. 93, No. 7, pp.1624-1629.

Wisconsin Department of Natural Resources (2010) Wisconsin's Chronic Wasting Disease Response Plan, 2010-2025 [online] http://dnr.wi.gov/topic/wildlifehabitat/documents/ CWD_15plan.pdf (accessed 22 August 2016).

Wisconsin Department of Natural Resources (2011) Almond Deer Farm Update, 22 November [online] http://dnr.wi.gov/about/nrb/2011/december/12-11-2b2.pdf (accessed 22 August 2016).

Wisconsin Department of Natural Resources (2015a) Trade and Consumer Protection. Farm-Raised Deer [online] http://datcp.wi.gov/Farms/Deer_Farming/index.aspx and Statute ACTP 10 (Subchapter VII) [online] http://docs.legis.wisconsin.gov/code/admin_code/ atcp/010/10.pdf (accessed 22 August 2016).

Wisconsin Department of Natural Resources (2015b) CWD Prevalence and Surveillance [online] http://dnr.wi.gov/topic/wildlifehabitat/prevalence.html (accessed 22 August 2016).

Wolfe, L.L., Spraker, T.R., Gonzalez, L., Dagleish, M.P., Sirochman, T.M., Brown, J.C., Jeffrey, M. and Miller, M.W. (2007) 'PrPCWD in rectal lymphoid tissue of deer (Odocoileus spp.)', Journal of General Virology, Vol. 88, No. 7, pp.2078-2082.

Zimmer, N., Boxall, P.C. and Adamowicz, W.L. (2011) 'The impact of chronic wasting disease and its management on hunter perceptions, opinions, and behaviors in Alberta, Canada', Journal of Toxicology and Environmental Health, Part A: Current Issues, Vol. 74, Nos. 22-24, pp.1621-1635.

Zimmer, N., Boxall, P.C. and Adamowicz, W.L. (2012) 'The impacts of chronic wasting disease and its management on recreational hunters', Canadian Journal of Agricultural Economics, Vol. 60, No. 1, pp.71-92. 


\section{Note added in proof}

The first case of CWD in a free-ranging Norwegian reindeer was discovered in the central region of Norway in March of 2016 (Benestad et al., 2016); subsequently, two additional cases in wild deer were discovered in the same area. Norway has decided to use hunters and sharpshooter to eradicate the entire herd of 2,000 animals in this area. Then, also in 2016, two cases of CWD in moose were discovered near Trondheim in northern Norway (Stokstad, 2017). The European Commission has asked the European Food Safety Authority (EFSA) to introduce surveillance and sampling activities in the entire northern sector of the European Union (Estonia, Finland, Iceland, Latvia, Lithuania, Norway, Poland and Sweden) with respect to the threat of CWD to seven wild, semi-domesticated and farmed cervid species: Eurasian tundra reindeer, Finnish (Eurasian) forest reindeer, moose, roe deer, white-tailed deer, red deer and fallow deer (Ricci et al., 2016). In addition, recent research on CWD in North America (Edmunds et al., 2016; Meyerett-Reid et al., 2017) includes a major review (Zabel and Ortega, 2017) of environmental factors in the spread and persistence of the cervid prion protein. Finally, a new risk control strategy has been proposed for CWD in North America, namely, using controlled burns of fires in forest areas where vegetation and soil is found to be heavily contaminated with prions.

\section{Additional references}

Benestad, S.L., Mitchell, G., Simmons, M., Ytrehus, B. and Vikøren, T. (2016) 'First case of chronic wasting disease in Europe in a Norwegian free-ranging reindeer', Veterinary Research, Vol. 47, p.88.

Edmunds, D.R., Kauffman, M.J., Schumaker, B.A., Lindzey, F.G., Cook, W.E., Kreeger, T.J. et al. (2016) 'Chronic wasting disease drives population decline of white-tailed deer', PLOS ONE, Vol. 11, No. 8, p.e0161127.

Meyerett-Reid, C., Wyckoff, A.C., Spraker, T., Pulford, B., Bender, H. and Zabel, M.D. (2017) 'De novo generation of a unique cervid prion strain using protein misfolding cyclic amplification', mSphere, Vol. 2, p.e00372-16.

Ricci, A. et al. (2016) 'Chronic wasting disease in cervids', EFSA Journal, Vol. 15, No. 1, p.4667.

Stokstad, E. (2017) 'Norway plans to exterminate a large reindeer herd to stop a fatal infectious brain disease', Science, 3 April, Vol. 356, No. 6344.

Zabel, M. and Ortega, A. (2017) 'The ecology of prions', Microbiology and Molecular Biology Reviews, Vol. 81, p.e00001-17. 